\title{
Corrigendum
}

\section{Corrigendum to "Umbilical Cord Hematoma: A Case Report and Review of the Literature"}

\author{
Gennaro Scutiero, ${ }^{1}$ Giulia Bernardi, ${ }^{1}$ Piergiorgio Iannone $\mathbb{D}^{1},{ }^{1}$ Luigi Nappi, ${ }^{2}$ \\ Danila Morano, ${ }^{1}$ and Pantaleo Greco ${ }^{1}$ \\ ${ }^{1}$ Department of Morphology, Surgery and Experimental Medicine, Section of Obstetrics and Gynecology, \\ Azienda Ospedaliero-Universitaria S. Anna, University of Ferrara, Via Aldo Moro 8, 44121 Cona, Ferrara, Italy \\ ${ }^{2}$ Department of Medical and Surgical Sciences, Institute of Obstetrics and Gynecology, University of Foggia, \\ Viale L. Pinto, 71100 Foggia, Italy
}

Correspondence should be addressed to Piergiorgio Iannone; pg.iannone88@gmail.com

Received 13 June 2018; Accepted 10 July 2018; Published 1 August 2018

Copyright (c) 2018 Gennaro Scutiero et al. This is an open access article distributed under the Creative Commons Attribution License, which permits unrestricted use, distribution, and reproduction in any medium, provided the original work is properly cited.

In the article titled "Umbilical Cord Hematoma: A Case Report and Review of the Literature" [1], the first and last names of the second author were reversed. The revised authors' list is shown above.

\section{References}

[1] G. Scutiero, B. Giulia, P. Iannone, L. Nappi, D. Morano, and P. Greco, "Umbilical cord hematoma: a case report and review of the literature," Obstetrics and Gynecology International, vol. 2018, Article ID 2610980, 6 pages, 2018. 


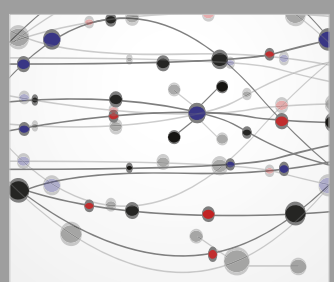

The Scientific World Journal
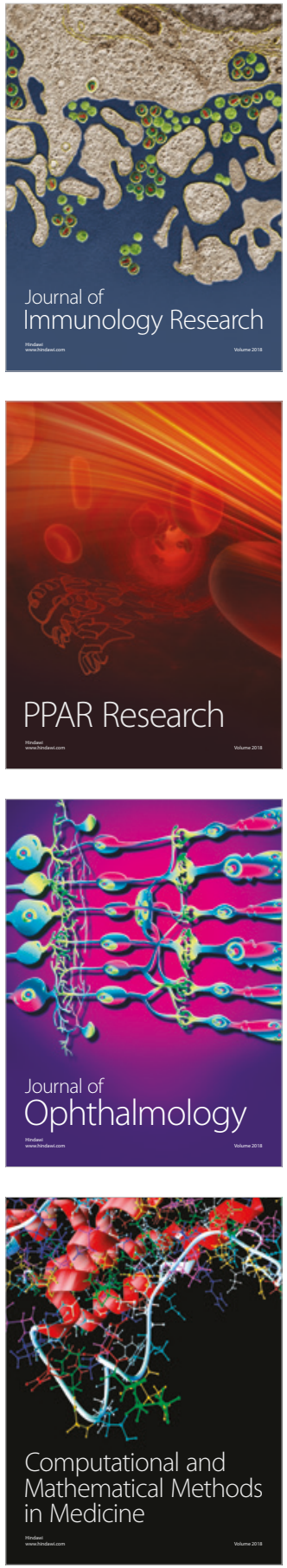

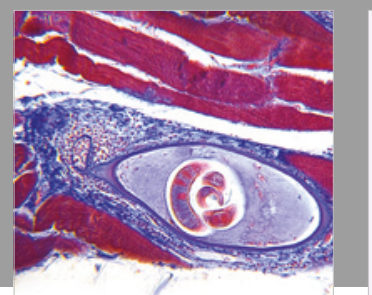

Gastroenterology Research and Practice

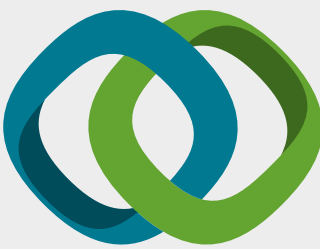

\section{Hindawi}

Submit your manuscripts at

www.hindawi.com
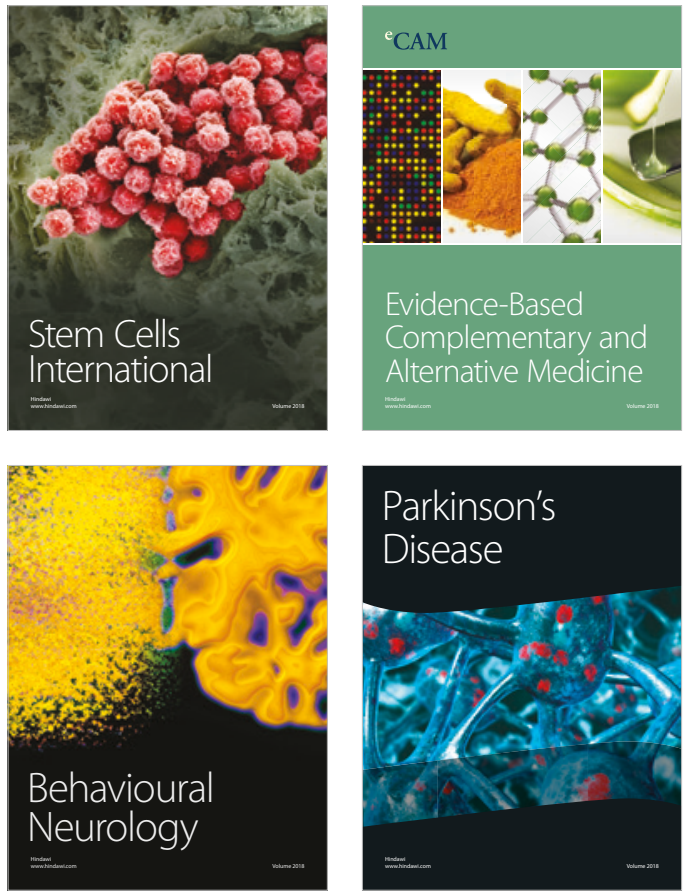

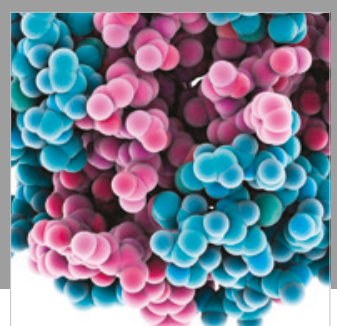

ournal of

Diabetes Research

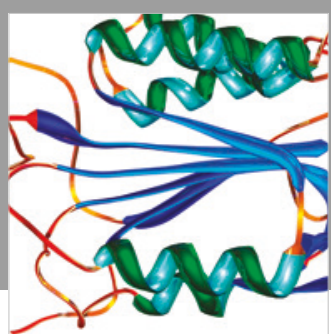

Disease Markers
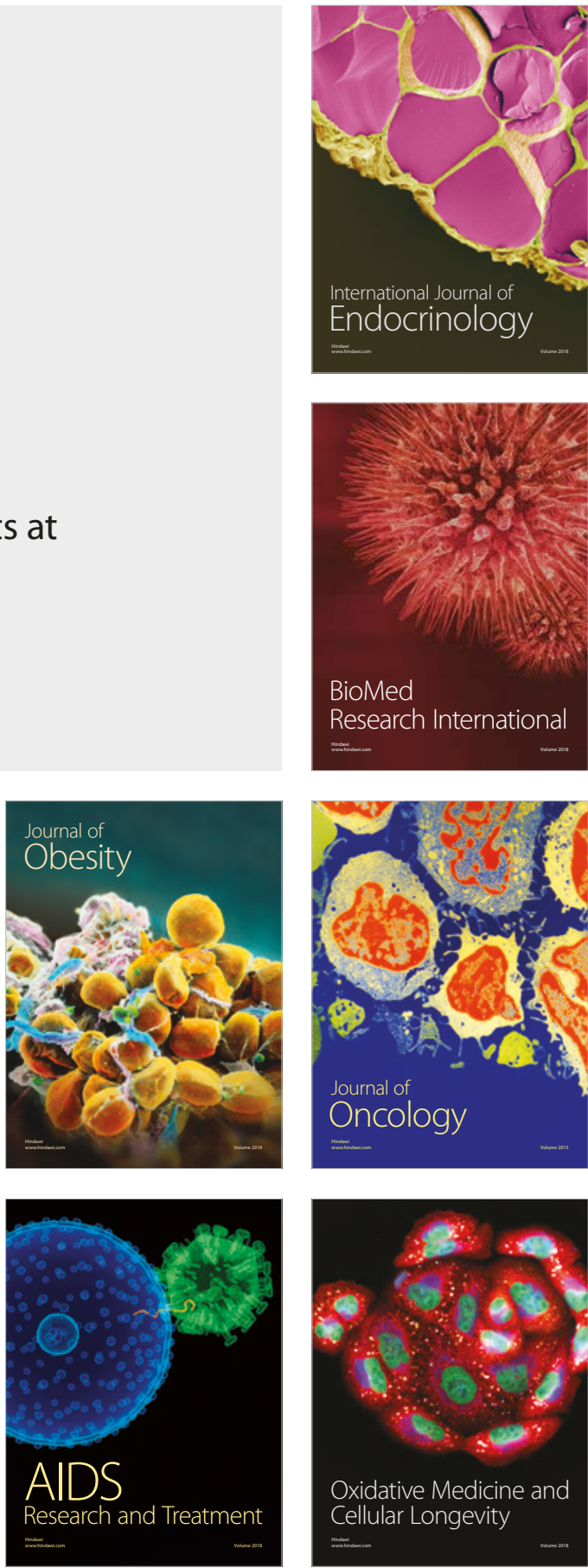